\title{
Deliberate selection of rocks in the construction of the Gummingurru Stone Arrangement Site Complex, Darling Downs, Queensland
}

\author{
Elena L. Piotto ${ }^{\mathrm{a}}$, Anne Ross ${ }^{\mathrm{a},},{ }^{*}$, Cassandra Perryman ${ }^{\mathrm{b}}$ and Sean Ulm ${ }^{\mathrm{c}}$ \\ ${ }^{\text {a }}$ School of Social Science, The University of Queensland, Brisbane, QLD 4072, Australia; ${ }^{b}$ School of Psychology, The \\ University of Queensland, Brisbane, QLD 4072, Australia; ${ }^{\mathrm{c}}$ ARC Centre of Excellence for Australian Biodiversity and \\ Heritage, College of Arts, Society and Education, James Cook University, PO Box 6811, Cairns, QLD 4870, Australia \\ *Corresponding author annie.ross@uq.edu.au
}

\begin{abstract}
This paper uses statistical analyses to examine the hypothesis that the creators of the Gummingurru Stone Arrangement Site Complex, southeast Queensland, deliberately selected rocks, based on size and shape, for the production of motifs at the site. As Gummingurru is an Aboriginal site, the literature that frames the research concerns Aboriginal cultural Law and worldviews. However, because the data are archaeological measurements, quantitative statistical methods are also employed. These quantitative results demonstrate deliberate selection of rocks occurred in the construction of four of the motifs at Gummingurru. We conclude that there are archaeological signatures of human behaviour in response to the requirements of cultural Laws with respect to the choice of raw materials, at least in stone arrangement sites.
\end{abstract}

\section{Introduction}

Aboriginal stone arrangements are a common feature in the Australian archaeological landscape (e.g. Barker et al. 2016; Black 1950; David et al. 2004; Fitzpatrick et al. in press; Hook and Di Lello 2010; Law et al. 2017; Macknight and Gray 1970; McCarthy 1940; McNiven 2004; Mullins et al. 1982; O'Connor 1987; O'Connor et al. 2007; Rowlands and Rowlands 1966; Rowland and Ulm 2011; Towle 1939). Nevertheless, while arrangements are routinely assessed and interpreted qualitatively, analysis of the placement of the rocks within them has not been undertaken. In this paper we hypothesise that the creators of stone arrangement sites deliberately selected certain rocks, based on their size and shape, for the production of motifs (Piotto 2012). We test this hypothesis by analysing four of the motifs from the Gummingurru Stone Arrangement Site Complex (Gummingurru) on the Darling Downs, southeast Queensland, using the extensive dataset collected by Ross and Ulm (2010).

\section{Gummingurru Stone Arrangement Site Complex}

Gummingurru is located in the Gowrie Creek catchment approximately $20 \mathrm{~km}$ northwest of Toowoomba, on the Darling Downs, southeast Queensland (Figure 1). The site is approximately 5 ha in size. Set in a natural amphitheatre, most of the Gummingurru site rests on exposed basalt capstone rock that is eroding due to natural environmental processes hastened by grazing. The site is covered by thousands of basalt rocks of various shapes and sizes. It is from these natural basalt outcrops that the unmodified rocks used to create the stone arrangements have been collected (Ross 2008; Ross and Ulm 2010).

Prior to European settlement, men gathered at Gummingurru from as far away as the New England plateau and across southeast, southwest and central Queensland to perform initiation ceremonies and conduct other activities such as trade and alliance maintenance en route to the triennial gatherings at the Bunya Mountains (French 1989; Gilbert 1992; Jerome 2002; Ross 2008; Ross and Ulm 2010; Tindale 1974; Whincop et al. 2012). Initiation ceremonies involved

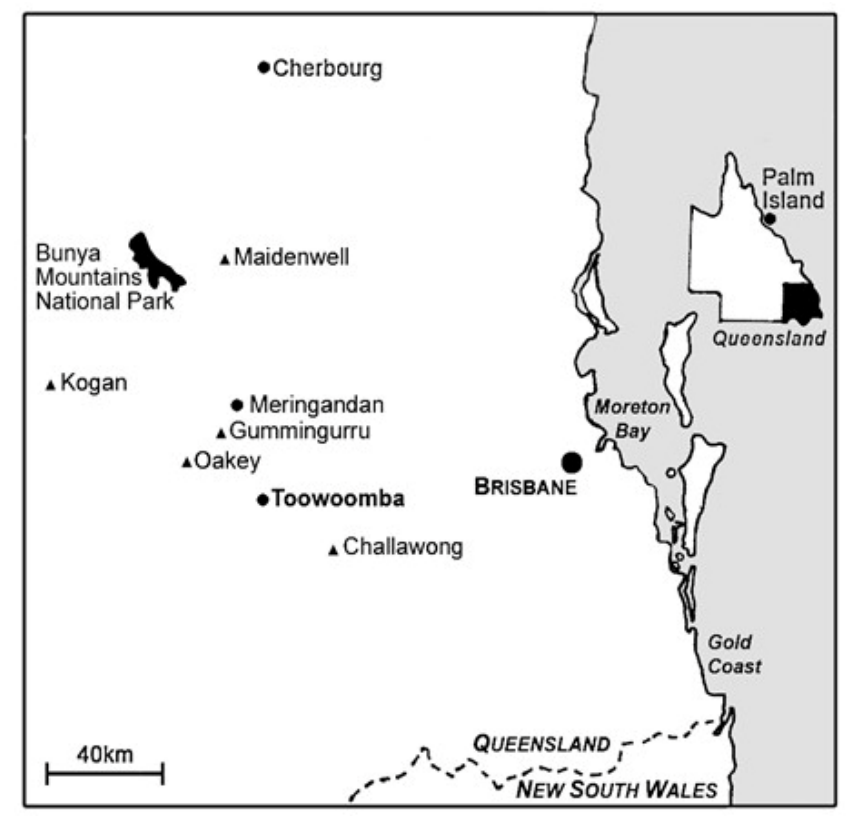

Figure 1. Figure 1. Southeast Queensland, showing location of Gummingurru (Ross 2008:92).

body scarification undertaken in the stone initiation ring, but also included the allocation of 'yurees' (totems), and the passing on of knowledge of how to manage yurees and their habitats, and other cultural Laws (Brian Tobane, pers. comm., 2008; see Ross 2008). The motifs that make up this complex stone arrangement site portray the yurees that were allocated, and those yuree motifs that remain easily visible on the site are interpreted by the Traditional Custodians as: a Carpet Snake; a Turtle (and its footprints); a Top-Knot Pigeon; an Emu; a Catfish; and a Bunya Nut. Other motifs on the site include a number of lines (some forming 'pathways'); waterholes (concentric circles of rocks); and 'star-bursts' (lines of rocks radiating out from a central core of rocks) (Figures 2-3).

During the contact period (1840s to 1860 s) the Traditional Custodians of Gummingurru - the Jarowair clan of the Wakka 


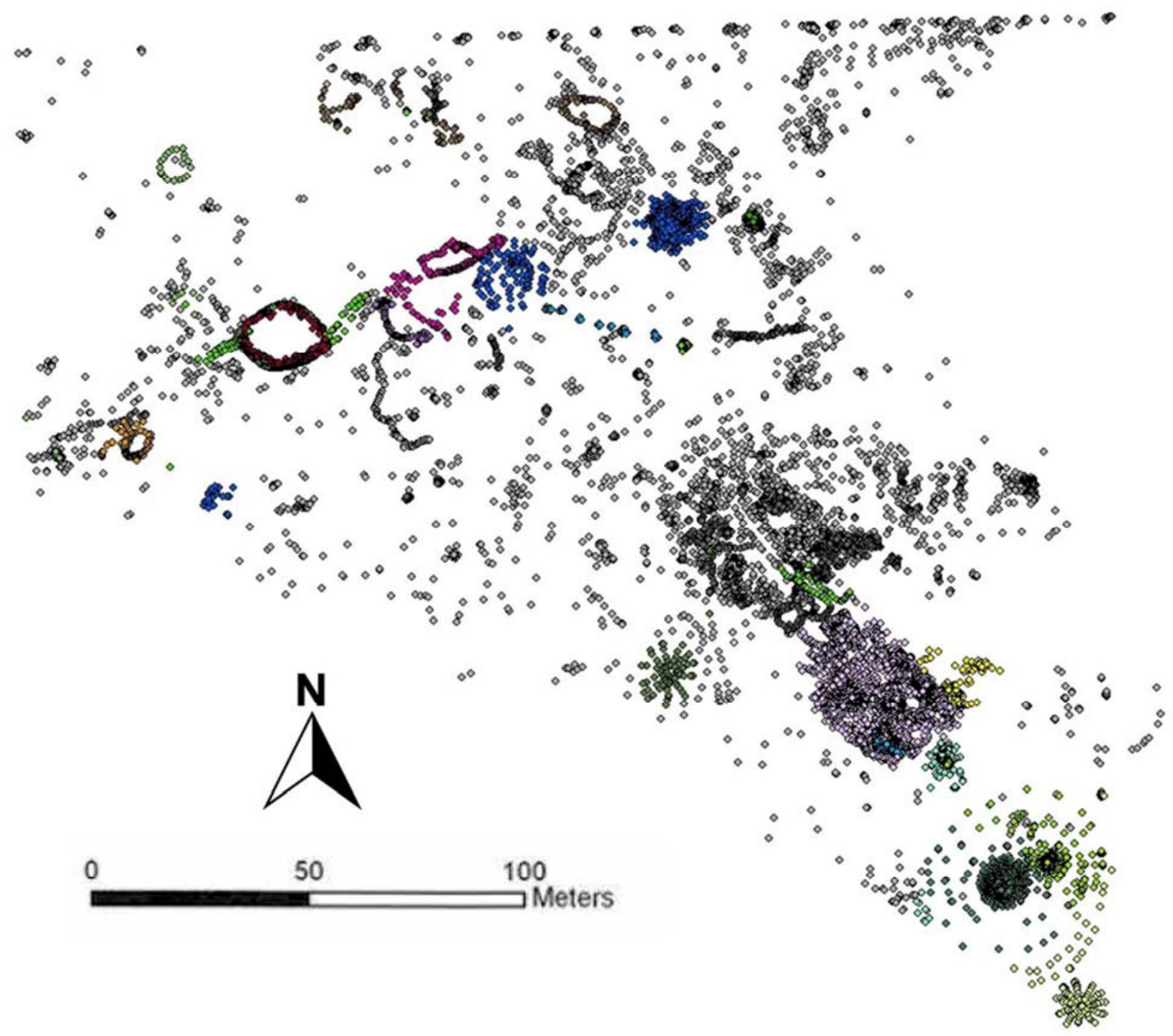

Figure 2. Map of the Gummingurru Stone Arrangement Site Complex showing all the recorded rocks (n=8848) and highlighting the motifs identified by the Traditional Custodians. From left to right the highlighted motifs are: Emu (yellow); Initiation Ring (and pathways) (red and green); Top-knot Pigeon (dark green); Carpet Snake (purple); Main Waterhole (blue); Bunya Nut (olive green); Second Waterhole (blue); Turtle Footprints and Turtle (emerald green); Small Star Burst (green); Pathway (clear); Large Starburst (bottom right). The Catfish motif cannot be discerned at this scale but is on the western side of the large mass of rocks between the Small Starburst and the Large Starburst. The apparent linear feature at the northern extent of the map is an artefact of the survey ceasing at the fenceline marking the current property boundary. Note that over 9000 rocks were recorded, however, for the purposes of this research only those more than $10 \mathrm{~cm}$ long and $10 \mathrm{~cm}$ wide were used $(n=8848)$. 


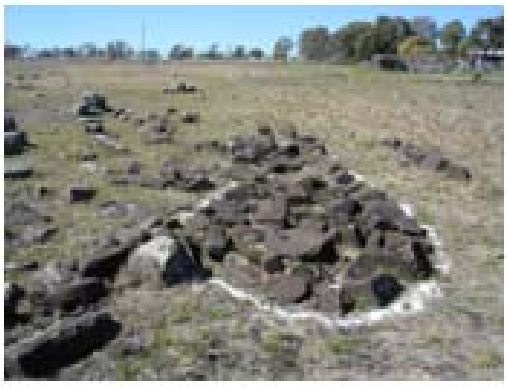

A

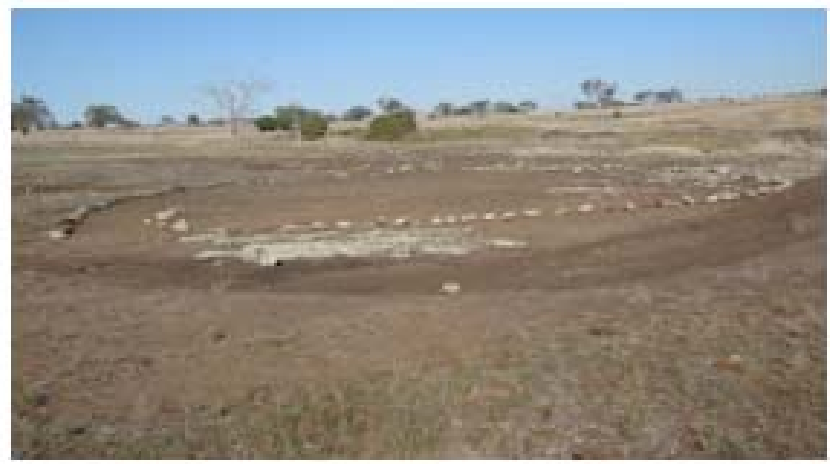

D

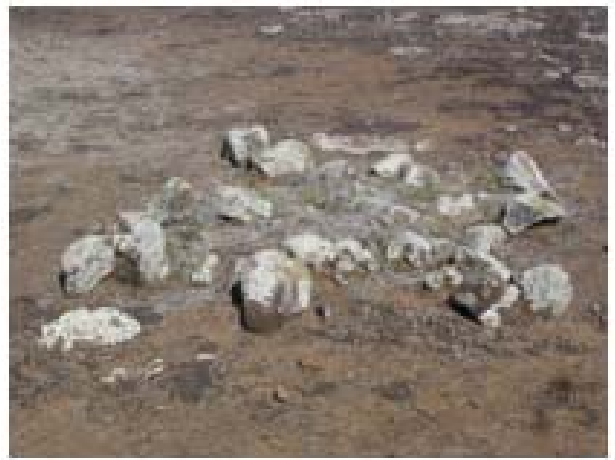

$\mathbf{F}$

B

G
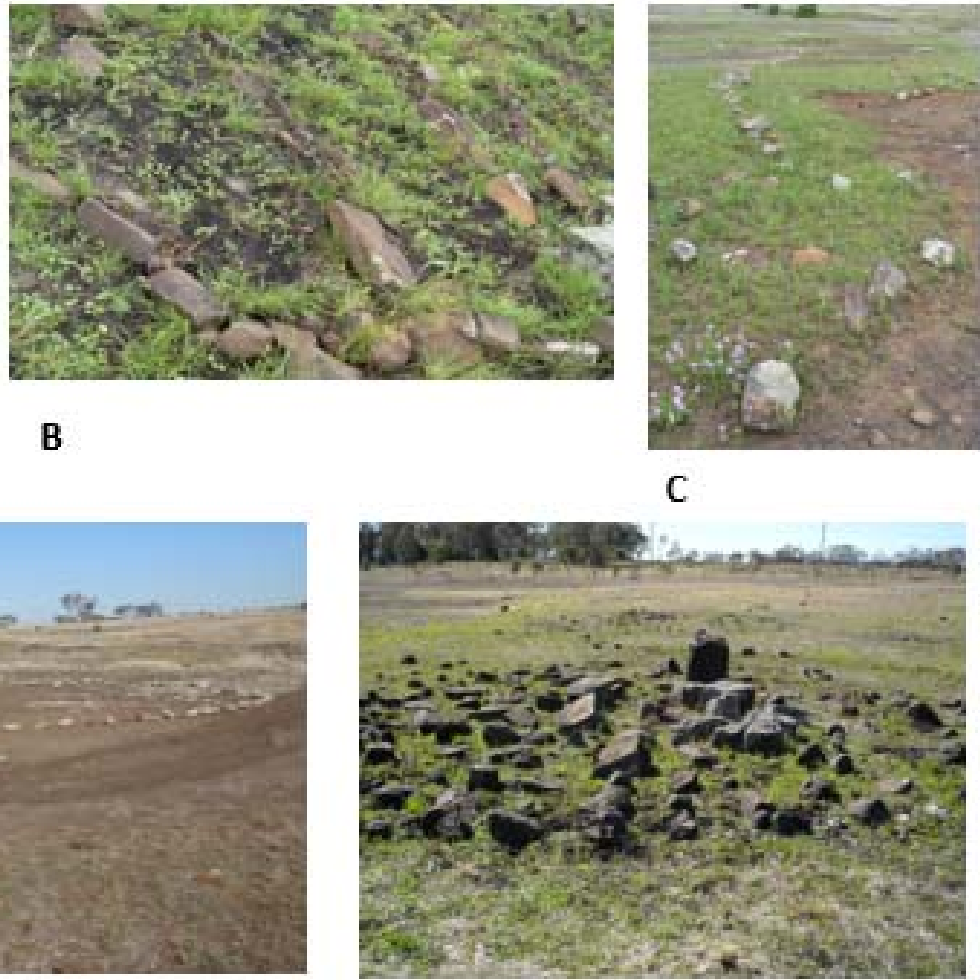

E

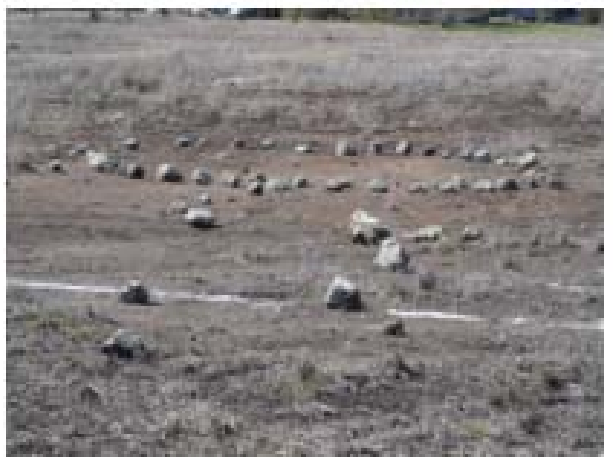

Figure 3. Images of Gummingurru motifs: (a) the Catfish in 2008, before the whiskers were resurrected; (b) the Catfish Whiskers; (c) the Carpet Snake; (d) the Initiation ring after maintenance in 2011; (e) the Large Starburst; (f) the Turtle; and (g) the Emu.

Wakka language group - were displaced from the site and it was not until September 2003, when the Indigenous Land Corporation (ILC) purchased the land on behalf of the Jarowair community, that they were formally reunited with the Gummingurru site (Ross and Ulm 2010).

Gummingurru remains an important place today for Jarowair and Wakka Wakka Traditional Custodians, and a number of other related groups (Jerome 2002; Ross 2008; Ross and Ulm 2010, Thomas and Ross 2013, 2018), although the activities conducted there have changed since pre-contact times. Education and cultural learning are still a major focus at Gummingurru but rather than the closed traditional ceremonies, today Gummingurru is open to the public with a purpose-built learning centre on site and tours for school groups and the general public (Ross et al. 2013).
Until his recent passing, Mr Brian Tobane, a senior Traditional Custodian, regularly tended to the 'old', previously recorded arrangements, and also 'resurrected' arrangements. Resurrection involved Mr Tobane probing the ground with a metal stake to locate buried rocks, which he would dig out and place on the surface immediately above their buried position (Ross et al. 2013). It is important to recognise that Tobane did not find new stones to add to motifs, nor did he move these buried rocks laterally. He simply raised buried rocks from below the ground to place on the surface immediately above their buried location. If 'new' motifs were discerned as a result of this activity, Tobane and the other Traditional Custodians are adamant that the 'new' motifs were originally on the ground surface but had been buried by slope wash over the years of Jarowair absence. 
Tobane's resurrection of the buried rocks was designed specifically to reinstate existing, but buried, motifs back onto the ground surface. Consequently, the Gummingurru site has a number of 'old' motifs, previously recognised and recorded by Bartholomai and Breeden (1961), as well as resurrected motifs not previously recorded. 'Old' motifs (naturalistic figures such as the Turtle, Snake, Bunya Nut and Emu) and the ceremonial ring dominate the arrangements, first recorded by Bartholomai and Breeden in 1959 (Bartholomai and Breeden 1961). The newly resurrected motifs tend to be more abstract (circles and lines), although some naturalistic motifs also occur amongst these recently uncovered motifs. Examples of the resurrected motifs include pathways, the Catfish, and 'Starbursts' (Ross 2008; Ross and Ulm 2010; Thomas and Ross 2013, 2018). As a result of their generally abstract form, these resurrected motifs are amongst the most contested motifs on the site and have been the subject of some conjecture as to whether they are features that have been imagined, or even created, by Tobane; for example, several local residents have challenged the existence of the new motifs, claiming that they were all 'fabricated' by Tobane and other Traditional Custodians to enhance the significance of the site (personal communication to Piotto, Ross and Ulm during survey and recording activities, 2008 to 2011). It was this conjecture, as well as the observed features of all the motifs, that led us to select a number of motifs for statistical analysis to determine whether they were deliberate creations, both ancient and recent.

\section{Resource Selection and Law Relating to Choice}

People select resources, sites, places, and activities based on a range of socio-cultural rules, or laws. Aboriginal Law governs the rights and responsibilities a person has to 'country', a term denoting the landscape and all it contains (Rose 1996; see also Bradley 2001). Aboriginal Law is informed by a 'mythico-cosmological' religious and spiritual doctrine that in turn informs all aspects of Aboriginal life (Godwin and Weiner 2006:125). It is this Law that connects living descendants of ancestors to country and its elements (Morphy 1995) and it is through the social structures thereby generated that decisions about the use of objects and sites are made (Bell 2002; Godwin 2005; Godwin and Weiner 2006; Zimmerman 2006).

We know, through oral history and historical documents, that Gummingurru was once a significant ceremonial and initiation site (Ross 2008) and would have, more than likely, had a more regulated set of rights and obligations under the Law than more general sites in the area, such as campsites (see discussions by Fletcher 1995; Mosely 2010; Wobst 2000). We hypothesise that the Law associated with Gummingurru shaped people's behaviour at the site, and particularly on the choices people made during the decision-making processes associated with the selection of rocks used in the design and construction of the motifs.

Ethnographic and archaeological research into resource selection demonstrates that the nature and method of resource selection is complex, incorporating social and political contexts that may go beyond the physical properties of the material being selected (McBryde 1984; Meehan and Jones 2005:161; Ross et al. 2003; Torrence 2005). In an effort to understand the culturally specific meanings of objects or places, biographies can be created that connect artefacts and sites to people, often as a result of the making of specific decisions relating to resource extraction (Appadurai 2006; Hodder 2012; Kopytoff 1986). Do such decision-making processes also extend to features in Indigenous Australian cultural landscapes, including stone arrangements? And can we identify such Laws in the archaeological record? In this paper we examine these questions in relation to the Gummingurru Stone Arrangement Site Complex.

\section{Methods}

The approach to this research is quantitative but set within constructivist theory. While a quantitative methodology and a constructivist paradigm are often said to be diametrically opposed and 'difficult to marry' (Greer 1996:107; Hodder and Hutson 2003; Scott 1996; Shanks and Tilley 1987), the research presented here shows that Gummingurru is an excellent case study to illustrate the value of combining both approaches in certain research contexts.

From the data recorded by Ross and Ulm (2010) and their team, 22 motifs have been identified (Figure 2). Four motifs were selected for detailed analysis for this study. The choice of motifs for analysis was based on three factors: motifs the Traditional Custodians wished to know more about; motifs that were demonstrably original arrangements, because they were first recorded in 1959, long before the return of the Traditional Custodians to the site; and motifs that have had their authenticity challenged because they are amongst those resurrected by Tobane and other Traditional Custodians since 2003. Based on these selection criteria, the four motifs chosen for analysis were: the Initiation Ring and the Carpet Snake, two examples of motifs originally recorded by Bartholomai and Breeden (1961), and thereby widely accepted as 'original, ancient' motifs on the site; the Large Starburst, an original motif recorded by Bartholomai and Breeden but identified and named 'Starburst' by Tobane in 2008; and the Catfish, a motif resurrected by Tobane over some time, from 2008 to 2010 (Ross et al. 2013), and the motif most widely criticised by many (non-Aboriginal) local residents who deem the Catfish to have been 'fabricated' by Tobane. We choose not to identify those who have made claims of fabrication of motifs. The claims were not made in any ethically approved research context but were mainly unsolicited (often quite acrimonious) verbal exchanges with the researchers and/or the Traditional Custodians during the research project.

ANOVA was chosen for the statistical analysis of the four motifs due to its robust calculation of independent group means. It is the preferred technique to achieve such complex analyses (Gamst et al. 2008). By separating the motifs from the site as a whole, five independent groupings were created: the Whole Site and the four motifs as outlined above.

It was decided to add the fifth grouping of the Whole Site to the analysis to compare the rocks used in the motifs against the rocks available on the site as a whole (including the rocks in the motifs). Because of the sheer quantity of rocks on this natural basalt outcrop, only rocks greater than $10 \mathrm{~cm}$ in maximum length were recorded. Even without these small rocks, 8848 rocks were recorded across the site - those that are part of motifs and those that are rocks in the landscape (Table 1; see also Ross and Ulm 2010). We do not believe that omitting smaller rocks from the sample has biased our results. The small rocks and pebbles on the site - amounting to tens of thousands of stones - occur everywhere. They are a general background 'noise' on the site both within motifs and in the general background. 
The four motifs were also divided into subfeatures as a heuristic device to compartmentalise the motifs to assist in the analysis of the large numbers of rocks. The determination of the subfeatures was made subjectively, based on the natural compartmentalisation of the naturalistic features of the motifs. So the Starburst was divided into rays and central rings; the Catfish into body, fins and whiskers; and so forth (see below). The differences between the rocks chosen to be included in each motif as a whole, between the individual features within each motif, and between the motifs and the background rocks ('Whole Site'), was assessed using statistical analyses (as outlined below). The statistical analyses were used to determine whether rock selection in the motifs was statistically random or statistically purposeful in design.

The subfeatures of each of the four motifs were as follows (see Figure $4 \mathrm{a}-\mathrm{d}$ ):

- The Catfish: body (including the head), fins, infill (including the ribs and spine), and whiskers

- Large Starburst: central ring, core, outer rings, and rays

- Initiation Ring: northern side, western path, eastern path, and southern side

- Carpet Snake: back, body, head, and tail.

These subfeatures were selected as they make up the essential elements of these naturalistic motifs:

- The Catfish is clearly a creature that comprises an external body, the bones and other infill features, its fins and its whiskers;

- The Starburst has a clear central core surrounded by an inner and outer ring, and rays;

- The Initiation Ring has only three distinct elements - the ring itself and the two pathways into and out of the ring. The division into northern and southern sides of the ring was a heuristic device to assist analysis; and

- The Carpet Snake, like the Catfish, has clear body elements of head, backbone, belly and tail.

Post hoc tests were undertaken where appropriate to determine where specific differences lie within each motif in accordance with the features identified above. Levene's Homogeneity of Variance test was used to test ANOVA assumptions and to evaluate the goodness of fit of the ANOVA results (Gamst et al. 2008).

\section{Results \\ Characterisation}

The first datasets investigated were those relating to the basic descriptive statistics for each of the analysed elements of the site: the Whole Site and the four motifs chosen for analysis. These are reported in terms of rock size (as measured by maximum length), and shape (as determined by the ratio between maximum length and maximum breadth) (Table 1).

\section{Whole Site}

A total of 8848 rocks was recorded and measured across the Whole Site. The range of rock sizes across the Whole Site is highly variable with the smallest recorded rocks at $10 \mathrm{~cm}$ in length and the largest at $170 \mathrm{~cm}$. More than $50 \%$ of recorded rocks across the Whole Site are under $20 \mathrm{~cm}$ long and more than $80 \%$ are under $30 \mathrm{~cm}$. For the length:width ratio, more than $55 \%$ of rocks across the Whole Site are under the 1.5:1 ratio and more than $80 \%$ are less than the $2: 1$ ratio. The shapes of the rocks across the site as a whole are, therefore, reasonably regular and mostly square in shape with only $20 \%$ being elongated - between ratios of 2:1 and 11.6:1 (the largest length:width ratio measured).

\section{Catfish}

Some $40 \%$ of rocks in the Catfish are smaller than $20 \mathrm{~cm}$ in length with $70 \%$ smaller than $30 \mathrm{~cm}$; the longest rock measures $68 \mathrm{~cm}$. Half of the rocks are cubic in shape, being less than $1.5: 1$, with nearly $75 \%$ having a shape characterised by a ratio of less than $2: 1$; the largest ratio is $7.7: 1$.

\section{Large Starburst}

Sixty percent of rocks in this motif are smaller than $20 \mathrm{~cm}$ in length, with just over $80 \%$ smaller than $30 \mathrm{~cm}$; the longest rock measures $65 \mathrm{~cm}$. Just over $55 \%$ of rocks are below the $1.5: 1$ ratio, with just over $85 \%$ of rocks below the $2: 1$ ratio, defining a largely cubic shape for the majority of rocks used. The largest ratio is 5.5:1.

\section{Initiation Ring}

Over $60 \%$ of rocks in the Initiation Ring are smaller than $20 \mathrm{~cm}$ in length, with $95 \%$ under $30 \mathrm{~cm}$; the largest rock in this motif measures $48 \mathrm{~cm}$. Sixty percent of rocks are below the $1.5: 1$ ratio, with $90 \%$ of rocks under the $2: 1$ ratio; the largest ratio is $5.7: 1$.

\section{Carpet Snake}

Thirty percent of rocks in the Carpet Snake motif are smaller than $20 \mathrm{~cm}$, with $75 \%$ smaller than $30 \mathrm{~cm}$ in length; the longest rock measures $44 \mathrm{~cm}$. Sixty percent of rocks are smaller than the $1.5: 1$ ratio, with some $90 \%$ of rocks under the $2: 1$ ratio; the largest ratio is $3.7: 1$.

\section{Summary}

Across the Whole Site most rocks are generally cubic in shape, with less than $20 \%$ being considered exceptionally elongated (being considerably more than twice as long as they are wide). There is also considerable variation in maximum length of rocks across the Whole Site, with recorded rocks ranging from $10 \mathrm{~cm}$ in length to very large bedrock outcrops up to $170 \mathrm{~cm}$ long. These very large rocks are much larger in size than the rocks used in the motifs. The range of sizes and shapes of rocks used in the four studied motifs is generally smaller than occurs across the Whole Site, with rocks used in the motifs being small in size (mostly less than $60 \mathrm{~cm}$ in length) and cubic in shape (few are more than twice as long as they are wide). This suggests that empirical observations of differences between rocks selected for use in motif construction, compared to those available on the site generally, may indeed be 'real'. Statistical analyses have been used to further test these observations of difference. 
A

$0.88 \%$
08.0

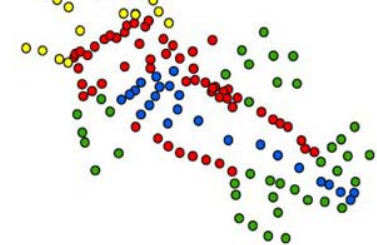

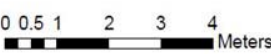

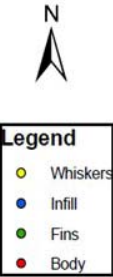

c

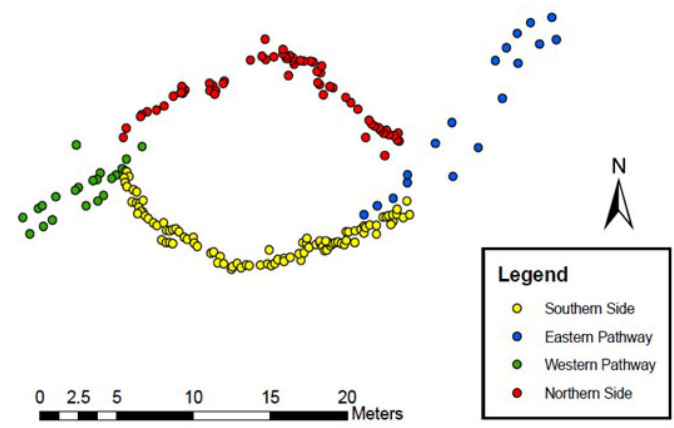

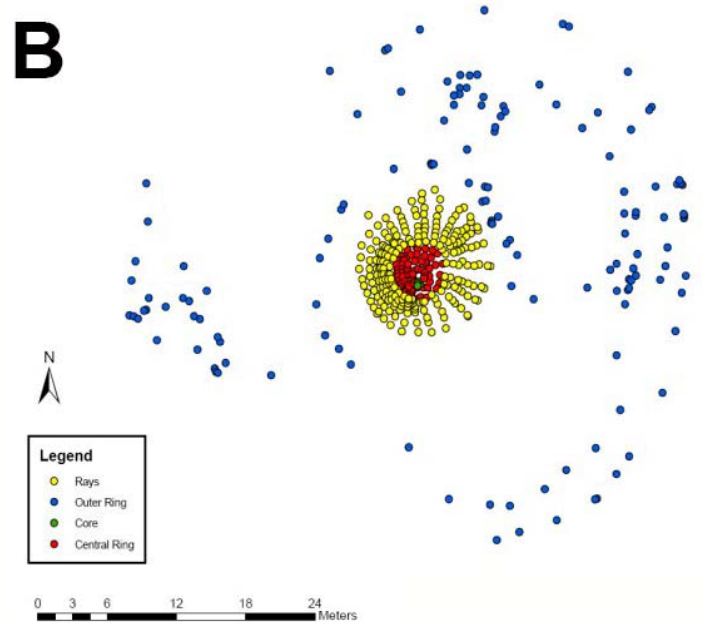

D

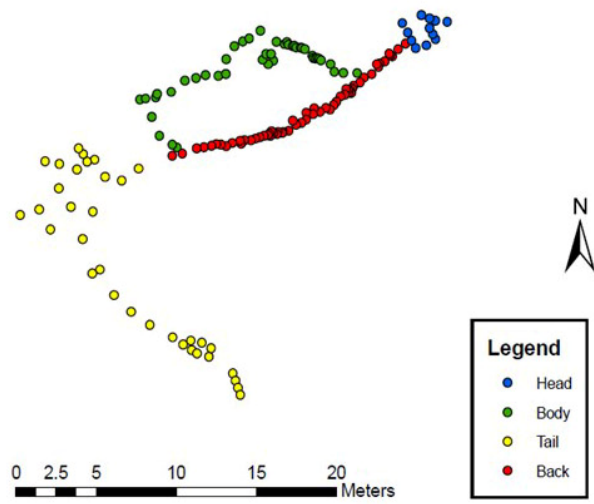

Figure 4. (a) Catfish motif subfeatures; (b) Large Starburst motif subfeatures; (c) Initiation Ring motif subfeatures; and (d) Carpet Snake motif subfeatures.

Table 1. Length and length:width ratio ranges of motifs. * Note minimum rock size recorded was $10 \mathrm{~cm}$ in maximum dimension.

\begin{tabular}{|l|c|c|c|c|c|}
\hline \multicolumn{1}{|c|}{ Motif } & $\begin{array}{c}\text { Number of } \\
\text { Recorded } \\
\text { Rocks }\end{array}$ & $\begin{array}{c}\text { Range of } \\
\text { Length } \\
\mathbf{( c m )}\end{array}$ & $\begin{array}{c}\text { Range of } \\
\text { Length:Width } \\
\text { Ratios }\end{array}$ & \% Rocks <20cm & \% Rocks <30cm \\
\hline Whole Site & 8848 & $10-170$ & $1: 1-11.6: 1$ & 50 & 80 \\
\hline Catfish & 157 & $10-68$ & $1: 1-7.67: 1$ & 40 & 70 \\
\hline Large Starburst & 431 & $10-65$ & $1: 1-5.5: 1$ & 60 & 80 \\
\hline Initiation Ring & 200 & $10-48$ & $1: 1-5.67: 1$ & 60 & 95 \\
\hline Carpet Snake & 149 & $10-44$ & $1: 1-3.71: 1$ & 30 & 75 \\
\hline
\end{tabular}




\section{ANOVA Analysis of Individual Motifs Compared to the Whole Site}

Analyses to compare size and shape characteristics using ANOVA were undertaken for each of the four case study motifs against the data for the Whole Site. These analyses were conducted to assess degrees of significant differences between the rocks chosen for use in the motifs against the rocks available for selection - i.e. the rocks available from across the Whole Site (see Table 2). Data were not trimmed (i.e. outliers were not removed from the analysis) so that the full integrity of the naturalistic data could be maintained. This resulted in there being unequal sample sizes between comparison groups. However, any bias created by group size variation was a bias towards a Type 1 error (negative) outcome (Zimmerman 2004), which leads to an understatement of significance. Data were also skewed from a normal distribution, but this will again produce a Type 1 error that understates significance (Gamst et al. 2008). Untransformed findings are reported here.

\section{Catfish vs. Whole Site}

ANOVA results for length show a significant difference between the length of rocks selected for use in the Catfish motif and those available across the Whole Site $(p<0.000)$ and shape of selected rocks $(\mathrm{p}<0.000)$. Specifically, the rocks in the Catfish motif are smaller and more regular/similar in shape to each other than to the rocks available across the Whole Site. These results imply that the rocks used to create the Catfish were deliberately chosen for both size and shape.

\section{Large Starburst vs. Whole Site}

ANOVA results showed no significant difference between the length of the rocks in the Whole Site as compared to the rocks used in the Large Starburst $(\mathrm{p}<0.344)$. ANOVA results for shape, however, indicate that the rocks that make up the Large Starburst were deliberately chosen for their shape compared to those found across the Whole Site $(\mathrm{p}<0.001)$. Specifically, the rocks in the Large Starburst are very similar to each other in their shape, being much more cubic than generally occurs across the Whole Site.

\section{Initiation Ring vs. Whole Site}

The ANOVA results for length indicate that the rocks that make up the Initiation Ring are significantly different in size compared to those that make up the Whole Site, being much smaller in size than those available across the Whole Site $(p<0.008)$. In terms of shape, like the rocks found in the Large Starburst, the rocks of the Initiation Ring are very similar to each other in shape, being more cubic than those found across the Whole Site. Nevertheless, results for shape show no significant difference between the Initiation Ring and the Whole Site $(p<0.560)$.

\section{Carpet Snake vs. Whole Site}

The ANOVA results for length indicate that the rocks that make up the Carpet Snake are significantly different in size compared to those across the Whole Site $(p<0.000)$. Like the rocks in the Initiation Ring, the rocks that make up the Carpet Snake are generally much smaller than those available across the site generally. The ANOVA results for shape indicate no significant difference between the rocks in the Carpet Snake and those found across the Whole Site $(\mathrm{p}<0.571)$.

\section{Summary}

When compared to the Whole Site it can be seen that the rocks selected for the four study motifs are between $60 \%$ and $75 \%$ smaller in length, and between $32 \%$ and $68 \%$ smaller in their length:width ratios, than the rocks available across the site as a whole. The results taken all together show that some level of deliberate selection, either for size or shape, or both, occurs in all of the case study motifs used for analysis when compared against the rocks available on the Whole Site, although not all differences are individually statistically significant differences. This initial statistical comparison led us to explore the results in more detail. Further comparative analyses between the motifs and Whole Site, as well as analyses of differences within the individual motifs, were undertaken.

\section{Analyses of Individual Motifs}

Post hoc analysis was undertaken on the rocks selected for the creation of the individual motifs to determine whether the features within each motif were significantly different from each other. Due to the nature of the data, a Tamhane's test was undertaken, as this test is based on assumptions that both variance and sample size are unequal (Gamst et al. 2008; Zimmerman 2004). Results are summarised in Table 3 for length, and Table 4 for length:width ratio.

\section{Catfish Motif}

As indicated above, the Catfish motif shows an overall significant difference in size of rocks chosen $(p<0.000)$ as well as an overall significant difference in shape of rocks chosen for the motif $(\mathrm{p}<0.000)$ as compared to the rocks available across the Whole Site. In addition, when the different elements within the Catfish are analysed, there are differences here too.

Post hoc analysis shows that specific significant differences lie between the length of rocks used in the body of the Catfish when compared to length of rocks in the fins $(p<0.011)$ (Table 3$)$. There are also significant differences in the shape of rocks in the body compared to those chosen for the creation of the whiskers $(\mathrm{p}<0.000)$, between the rocks in the whiskers and the infill $(\mathrm{p}<0.008)$, and between the whiskers and the fins $(\mathrm{p}<0.016)$ (Table 4). These differences suggest purposeful design of the Catfish motif, most notably in the choice of rock shape where elongated rocks, in particular, have been especially chosen in the creation of the whiskers, which are clearly a distinct formation in front of the head of the Catfish motif.

\section{Large Starburst Motif}

As indicated above, the features of the Large Starburst motif show an overall significant difference in shape of rocks chosen for the motif $(\mathrm{p}<0.001)$.

Post hoc analysis shows that significant differences lie between the length of rocks used in the creation of almost all of the subfeatures of this motif (Table 3). For example, the central ring of the Large Starburst has rocks of different length when compared to the rocks used in the outer rings $(p<0.000)$ and the rays $(p<0.000)$. Some of the most significant 
differences lie between the rays and the rest of this motif: the rays and the outer ring $(p<0.033)$, the core $(p<0.000)$ and the central ring $(p<0.000)$. These same features showed a significant difference in shape (Table 4), with the rocks used in the central ring being less elongated in shape compared with those used in both the outer ring $(\mathrm{p}<0.007)$ and the rays $(p<0.008)$. Overall, these statistically significant differences suggest purposeful and deliberate choice of certain rocks to portray specific features of this motif during its construction.

\section{Initiation Ring Motif}

No post hoc testing was undertaken for this motif, as there were no significant differences between rock sizes across the motif. Post hoc testing was undertaken to identify whether variations within motifs (i.e. between subfeatures) was significant. For the Initiation Ring, the ubiquitous regularity of the rock size and shape for each rock right across this motif was demonstrated during recording. This regularity in size and shape was far more so than for the rocks occurring across the Whole Site. The uniformity of rocks selected in the creation of this motif make it unique amongst the other motifs analysed for this study, as we will discuss below.

\section{Carpet Snake Motif}

Initial ANOVA analysis of the Carpet Snake motif showed a significant difference between length of rocks in the motif compared to the rocks available for selection across the Whole Site $(\mathrm{p}<0.000)$, but no significant difference in length:width ratio (i.e. shape) $(\mathrm{p}<0.571)$.

Post hoc analyses were conducted for the length of the rocks in the features of the Carpet Snake motif. Differences were found between the back and belly $(p<0.002)$, as well as back and tail features $(\mathrm{p}<0.001)$. Differences were also found between the head and belly $(\mathrm{p}<0.007)$ and head and tail features $(p<0.003)$. In short, the rocks selected for the back and head features of the Carpet Snake are significantly longer than those used in the belly and tail components of the motif.

\section{Summary}

The ANOVA analyses show that there are elements of nonrandomness in the choice of rocks selected for the creation of the following: the Catfish for both size and shape of rocks selected; the Large Starburst for shape of rocks selected; the Initiation Ring for size of rocks used; and the Carpet Snake for size of rocks chosen as compared to rocks used across the Whole Site. In addition, the individual motifs showed that there were other aspects of difference within the features of three of the four motifs (see Table 2) and that these differences are significant. The analyses show that the rocks in the four case study motifs at Gummingurru display a deliberate patterning that indicates that the choice of specific sizes and/or shapes of rocks chosen from the available pool of rocks was indeed a factor in the creation of the motifs in the stone arrangements.

\section{Discussion and Conclusion}

The focus of this research has been to determine whether specific choices were made in the selection of rocks for the creation of some of the individual arrangements of rocks into naturalistic motifs at the Gummingurru site in the past and, specifically, if it is possible to identify selection strategies in the archaeological record at Gummingurru. Using statistical analyses, we have been able to determine that there is indeed evidence for the deliberate selection of certain rocks for the creation of some motifs.

The quantitative analyses show that the people responsible for the creation of the Gummingurru stone arrangement site were deliberately preferencing rocks of certain sizes and shapes for the construction of the motifs used to depict the yurees of the initiands; for example, there was far greater uniformity in the rocks chosen for the creation of the Initiation Ring than occurs across the site as a whole; and in the Catfish motif, the shape of the rocks, particularly those used to delineate particular features of the animal, such as its whiskers, is significantly different from the shape of the rocks across the site as a whole, and from the rocks used in the rest of the motif. The analysis of the Catfish, in particular, strongly supports the views of the Traditional Custodians that the motif was indeed a part of the original stone arrangement complex, buried by depositional soil movement processes since contact, rather than an imagined motif fabricated from the processes associated with Tobane's 'resurrection' methods.

Table 2. ANOVA results for difference between the individual motifs and the Whole Site (significant results highlighted).

\begin{tabular}{|c|c|c|}
\hline Motif & $\begin{array}{c}\text { Length between the } \\
\text { Whole Site and the } \\
\text { Motif }\end{array}$ & $\begin{array}{c}\text { Length:Width Ratio } \\
\text { between the Whole Site } \\
\text { and the Motif }\end{array}$ \\
\hline Catfish & $\begin{array}{c}\mathrm{F}(1,9003)=38.029 \\
<\mathbf{0 . 0 0 0}\end{array}$ & $\begin{array}{c}\mathrm{F}(1,9003)=33.199 \\
<\mathbf{0 . 0 0 0}\end{array}$ \\
\hline Large Starburst & $\begin{array}{c}\mathrm{F}(1,9277)=0.895 \\
<0.344\end{array}$ & $\begin{array}{c}\mathrm{F}(1,9277)=11.573 \\
<\mathbf{0 . 0 0 1}\end{array}$ \\
\hline Initiation Ring & $\begin{array}{c}F(7,9046)=7.079 \\
<\mathbf{0 . 0 0 8}\end{array}$ & $\begin{array}{c}\mathrm{F}(7,9046)=0.339 \\
<0.560\end{array}$ \\
\hline Carpet Snake & $\begin{array}{c}\mathrm{F}(1,8995)=17.726 \\
<\mathbf{0 . 0 0 0}\end{array}$ & $\begin{array}{c}\mathrm{F}(1,8995)=0.320 \\
<0.571\end{array}$ \\
\hline
\end{tabular}


Table 3. Summary of post hoc results for difference in length of rocks between the subfeatures of motifs (significant results highlighted).

\begin{tabular}{|l|l|l|l|l|l|l|l|l|}
\hline \multicolumn{1}{|c|}{ Motif } & \multicolumn{1}{|c|}{ Subfeatures } & \multicolumn{1}{|c|}{ Sig } & \multicolumn{1}{|c|}{ Subfeatures } & \multicolumn{1}{|c|}{ Sig } & \multicolumn{1}{|c|}{ Subfeatures } & \multicolumn{1}{c|}{ Sig } & \multicolumn{1}{c|}{ Subfeatures } & \multicolumn{1}{c|}{ Sig } \\
\hline Catfish & Body vs fins & $\mathbf{0 . 0 1 1}$ & Fins vs body & $\mathbf{0 . 0 1 1}$ & Infill vs body & 1.000 & Whiskers vs body & 1.000 \\
& vs infill & 1.000 & vs infill & 0.111 & vs fins & 0.111 & vs fins & 0.144 \\
& vs whiskers & 1.000 & vs whiskers & 0.144 & vs whiskers & 1.000 & vs infill & 1.000 \\
\hline Large & Central ring vs core & 0.153 & Core vs central ring & 0.153 & Outer rings vs core & $\mathbf{0 . 0 0 0}$ & Rays vs core & $\mathbf{0 . 0 0 0}$ \\
Starburst & vs outer rings & $\mathbf{0 . 0 0 0}$ & vs outer rings & $\mathbf{0 . 0 0 0}$ & vs central ring & $\mathbf{0 . 0 0 0}$ & vs central ring & $\mathbf{0 . 0 0 0}$ \\
& vs rays & $\mathbf{0 . 0 0 0}$ & vs rays & $\mathbf{0 . 0 0 0}$ & vs rays & $\mathbf{0 . 0 3 3}$ & vs outer rings & $\mathbf{0 . 0 3 3}$ \\
\hline Carpet & Back vs belly & $\mathbf{0 . 0 0 2}$ & Belly vs back & $\mathbf{0 . 0 0 2}$ & Head vs back & 1.000 & Tail vs back & $\mathbf{0 . 0 0 1}$ \\
Snake & vs head & 1.000 & vs head & $\mathbf{0 . 0 0 7}$ & vs belly & $\mathbf{0 . 0 0 7}$ & vs belly \\
& vs tail & $\mathbf{0 . 0 0 1}$ & vs tail & 1.000 & vs tail & $\mathbf{0 . 0 0 3}$ & vs head \\
\hline
\end{tabular}

Table 4. Summary of post hoc results for difference in length:width ratio of rocks between the subfeatures of motifs (significant results highlighted).

\begin{tabular}{|l|l|l|l|l|l|l|l|l|}
\hline \multicolumn{1}{|c|}{ Motif } & \multicolumn{1}{|c|}{ Subfeatures } & Sig & \multicolumn{1}{|c|}{ Subfeatures } & \multicolumn{1}{c|}{ Sig } & \multicolumn{1}{|c|}{ Subfeatures } & \multicolumn{1}{c|}{ Sig } & \multicolumn{1}{c|}{ Subfeatures } & \multicolumn{1}{c|}{ Sig } \\
\hline Catfish & Body vs fins & 1.000 & Fins vs body & 1.000 & Infill vs body & 1.000 & Whiskers vs body & $\mathbf{0 . 0 0 0}$ \\
& vs infill & 1.000 & vs infill & 1.000 & vs fins & 1.000 & vs fins & $\mathbf{0 . 0 1 6}$ \\
& vs whiskers & $\mathbf{0 . 0 0 0}$ & vs whiskers & $\mathbf{0 . 0 1 6}$ & vs whiskers & $\mathbf{0 . 0 0 8}$ & vs infill & $\mathbf{0 . 0 0 8}$ \\
\hline Large & Central ring vs core & 1.000 & Core vs central ring & 1.000 & Outer rings vs core & 0.215 & Rays vs core & 0.246 \\
Starburst & vs outer rings & $\mathbf{0 . 0 0 7}$ & vs outer rings & 0.215 & vs central ring & $\mathbf{0 . 0 0 7}$ & vs central ring & $\mathbf{0 . 0 0 8}$ \\
& vs rays & $\mathbf{0 . 0 0 8}$ & vs rays & 0.246 & vs rays & 1.000 & vs outer rings & 1.000 \\
\hline
\end{tabular}


This latter point is important in the context of the interpretation of the Gummingurru site. Gummingurru today is used as a place of reconciliation, where school students, in particular, are brought to learn about Aboriginal culture. The challenge, by some in the local community, that at least some aspects of the site are inauthentic - fabricated by the Traditional Custodians to elevate the significance of the place and to create an invented narrative of the site and its history is hurtful to the Traditional Custodians. While it is probably inevitable that minor horizontal and lateral changes may have occurred in lifting and replacing rocks (a few centimetres at most, though we have no evidence of this), our research demonstrates that the resurrection activities of Tobane and other Custodians has not resulted in the recent creation of motifs. At least in terms of the Catfish, the raised stones not only form the clearly visible outline of a Catfish, the stones are also very much in keeping with the stone used in other motifs on the site, with deliberately selected rocks to form some of the peculiar features of the motif, in this case the Catfish's whiskers. Given that one of us (AR) watched Tobane working on the site over many years, observing him raise rocks and carefully place them on the ground surface without altering their original lateral position, we are confident of the authenticity of the resurrection of the Catfish, and other resurrected motifs on the site.

The careful selection of certain rocks, based on their size and shape, has been documented by other researchers investigating stone arrangement sites. For example, McNiven (2004) noted the regularity in the size of rocks used in the construction of curvilinear stone arrangements in Shoalwater Bay, northeast Queensland, and Barker et al. (2016) made similar observations on the size of rocks used in the construction of curvilinear stone arrangements extending for over $2 \mathrm{~km}$ along the coast of Mine Island, central Queensland. McNiven (2004) and Barker et al. (2016) argue that stone arrangements of these types are linked to ritual performances as part of people's engagement with spiritscapes in an effort to control tidal extent. But neither McNiven (2004) nor Barker et al. (2016) went on to consider the role that size and shape of rocks had on the Law of rock selection for the construction of the stone arrangements.

The question to be addressed now is: could the evidence for deliberate choice demonstrated in the current study be explained with reference to the literature on choice in other aspects of Aboriginal Law and cultural practice? Using the concept of Aboriginal Law as an overarching theme, can the data from Gummingurru relating to choice be interpreted in a social and cultural framework?

While there has been extensive literature devoted to understanding choice in relation to lithic production, art production, food gathering, and other subsistence activities (e.g. Bell 2002; Godwin 2005; Godwin and Weiner 2006; Graf and Goebel 2009; McBryde 1984; Meehan and Jones 2005; Ross et al. 2003; Taçon 1994; Torrence 2005; Zimmerman 2006), we have not found any literature relating to the existence of Law for the selection of rocks in stone arrangements.

In this paper, to address this absence of literature relating to the concept of 'choice' in the selection of rocks for the construction of a stone arrangement, quantitative data analyses were used to examine four motifs from Gummingurru. This methodological approach allowed us to determine that there were patterns in the selection and placement of the rocks that form the case study motifs. The results of the statistical analyses lead us to question whether any patterns found could be explained as being the result of deliberate selection, and could any deliberate selection be the result of cultural Laws (see Piotto 2012 for a detailed assessment).

Considerable anthropological research has documented that Aboriginal people 'read' natural and landscape features; there is an inherent understanding of the ritual properties of objects in the landscape, especially stone (e.g. Meehan and Jones 2005) and the semiotic nature of the rock itself (e.g. Bradley 2008; Povinelli 1995). Thus, objects and rocks can also be 'read', telling people of their ('the rocks') powers (e.g. Jones and White 1988) or that they are either 'ready' or 'not ready' for use: flaking in the case of some stone points (Jones and White 1988), or incorporation into stone arrangement motifs, as demonstrated here. This ability to 'read' rocks has been widely demonstrated in terms of Aboriginal people's knowledge of the 'life' of rocks as a method for the selection of appropriate rocks for use in artefact manufacture. We suggest that, based on the research reported here, the rocks which form the motifs at Gummingurru were also 'read' by the people creating at least some of the motifs at the site. Our study demonstrates that certain rocks were chosen for use in specific motifs or parts of motifs - elongated rocks for the Catfish, especially the whiskers; very regularly shaped rocks in the Initiation Ring etc. We contend that these especially chosen rocks were placed deliberately, according to Law.

This observation, by extension, can be seen as Aboriginal Law pertaining to choice being applied to a stone arrangement. The actions of the people in choosing the rocks to be used in the motifs may have been in response to the widely-held rationale of Laws about choice: to avoid sickness, injury, or (in extreme cases) death. Given that Gummingurru was a very special site in pre-contact times, being a men's ceremonial and initiation site (Ross 2008; Ross and Ulm 2010; Ross et al. 2013; Thomas and Ross 2013, 2018), and given that special sites are never random (e.g. Bradley 2010; Rose 1996), the consequences of improper behaviour at this site could have been dire. Therefore, the behaviour and actions of people at Gummingurru, including the act of creating the motifs and the stone arrangement as a whole, are likely to have been very closely monitored so as not to incur punishment from spirit beings.

These observations have wider implications for the discipline of archaeology and cultural heritage management than simply the choice of rocks in the creation of a particular site. These powerful forces associated with Law are an 'ever present fact of life' for Aboriginal people (Macdonald 2001:176). However, archaeological analyses of artefacts have shown a 'conspicuous absence' of acknowledgement for this worldview (Mosely 2010:69). While archaeologists and cultural heritage managers are able to assess an area using quantitative analytical methods, we argue that they must also engage with the artefacts they encounter in a social way recognising a metaphysical relationship between people and objects, and between people and place (Bradley 2008; Mosely 2010). This relationship has been underdeveloped (Byrne 2005; Mosely 2010) as it falls outside the boundaries of the traditional framework of the discipline and delves into the more esoteric, intangible qualities of the artefact/s (which are not measurable). However, using research methods such as those outlined here, which we have used in this new and 
innovative way, social understandings of how a site was created or developed are possible. Using a constructivist paradigm combined with a quantitative methodology not only highlights the intangible qualities of artefacts (in this case a stone arrangement) but also uses the reductive characteristics of archaeology (Byrne 1996:87) to test the significance of these intangible qualities.

\section{Acknowledgements}

Permission to conduct this research and to write this paper was received from members of the Gummingurru Aboriginal Corporation, particularly Jarowair Traditional Custodians of the site. We would like particularly to acknowledge the support and collaboration in this work of the following Traditional Custodians: the late Brian Tobane, David Tobane, Paddy Jerome, Tommy Daniels, Conrad Bauwens and Shannon Bauwens. The research was funded by the Australian Institute of Aboriginal and Torres Strait Islander Studies (G07/7246 and 2008/004543). The paper has benefitted from conversations with Jane Lavers, E. Jaydeyn Thomas, Steve Nichols and Joel Deacon and from comments provided by Denis Byrne, Nathan Woolford and three other referees. Many thanks to all of the archaeology students from all over Australia who have braved cold winds and fierce heat in working together on the project. SU is the recipient of an Australian Research Council Future Fellowship (project number FT120100656). Work on this paper was undertaken while SU was visiting as an Honorary Fellow in the School of Social Sciences, The University of Western Australia.

\section{References}

Appadurai, A. 2006 The thing itself. Public Culture 18(1):15-21. https://doi.org/10.1215/08992363-18-1-15

Barker, B., L. Lamb and G. Campbell 2016 The Mine Island Aboriginal stone arrangements: Spiritual responses to late Holocene change on the central Queensland coast. Australian Archaeology 82(3):232-247. https://doi.org/10.1080/03122417.2016.1251725

Bartholomai, A. and S. Breeden 1961 Stone ceremonial ground of the Aborigines in the Darling Downs area, Queensland. Memoirs of the Queensland Museum 13(6):231-237.

Bell, D. 2002 Daughters of the Dreaming. 3rd ed. Melbourne: Spinifex Press.

Black, L. 1950 Stone Arrangements: Being a Continuation of a Series on the Customs of the Aborigines of the Darling River Valley and of Central New South Wales. Perth, WA: Paterson Brokensha.

Bradley, J.J. 2001 Landscapes of the mind, landscapes of the spirit: Negotiating a sentient landscape. In R. Baker, J. Davies and E. Young (eds), Working on Country: Contemporary Indigenous Management of Australia's Lands and Coastal Regions, pp.295307. Melbourne: Oxford University Press.

Bradley, J.J. 2008 When a stone tool is a dingo. In B. David and J. Thomas (eds), Handbook of Landscape Archaeology, pp.633637.Walnut Creek, CA: Left Coast Press.

Bradley, J.J. 2010 Singing Saltwater Country: Journey to the Songlines of Carpentaria. Sydney: Allen and Unwin.

Byrne, D. 1996 Deep nation: Australia's acquisition of an indigenous past. Aboriginal History 20:82-107.

Byrne, D. 2005 Messages to Manilla. In I. Macfarlane, M.J. Mountain and R. Paton (eds), Many Exchanges: Archaeology, History, Community and the Work of Isabel McBryde, pp.53-62. Aboriginal History Monograph 11. Canberra: Aboriginal History Inc.
David, B., I.J. McNiven, Mura Badulgal Corporation Committee, J. Crouch and L. Brady 2004 The Argan stone arrangement complex, Badu: Initial results from Torres Strait. Australian Archaeology 58:1-6. https://doi.org/10.1080/03122417.2004.11681773

Fitzpatrick, A., I.J. McNiven, J. Specht and S. Ulm in press Stylistic analysis of stone arrangements supports regional cultural interactions along the northern Great Barrier Reef, Queensland. Australian Archaeology.

Fletcher, R. 1995 The Limits of Settlement Growth: A Theoretical Outline. Cambridge: Cambridge University Press.

French, M. 1989 Conflict on the Condamine: Aborigines and the European Invasion. Toowoomba: Darling Downs Institute Press.

Gamst, G., L.S. Meyers and A.J. Guarino 2008 Analysis of Variance Design. New York: Cambridge University Press.

Gilbert, B. 1992 Who Bide in Ancient Valleys. Gowrie Junction, QLD: Ben Gilbert.

Godwin, L. 2005 'Everyday archaeology': Archaeological heritage management and its relationship to native title in development related processes. Australian Aboriginal Studies 1:74-82.

Godwin, L. and J.F. Weiner 2006 Footprints of the ancestors: The convergence of anthropological perspectives in contemporary Aboriginal heritage studies. In B. David, B. Barker and I.J. McNiven (eds), The Social Archaeology of Australian Indigenous Societies, pp.124-138. Canberra: Aboriginal Studies Press.

Graf, K.E. and T. Goebel 2009 Upper Paleolithic toolstone procurement and selection across Beringia. In B. Adams and B.S. Blades (eds), Lithic Materials and Palaeolithic Societies, pp.54-77. London: Wiley-Blackwell.

Greer, S. 1996 Archaeology, heritage and identity in northern Cape York Peninsula. In S. Ulm, I. Lilley and A. Ross (eds), Australian Archaeology '95: Proceedings of the 1995 Australian Archaeological Association Annual Conference, pp.103-110. Tempus 6. St Lucia, QLD: Anthropology Museum, University of Queensland.

Hodder, I. 2012 Entangled: An Archaeology of the Relationships between Humans and Things. London: Wiley-Blackwell.

Hodder, I. and S. Hutson 2003 Reading the Past: Current Approaches to Interpretation in Archaeology. 3rd ed. Cambridge: Cambridge University Press.

Hook, F. and A. Di Lello 2010 Gurdadaguji stone arrangements: Late Holocene aggregation locals? In D. Calado, M. Baldia and M. Boulanger (eds), Monumental Questions: Prehistoric Megaliths, Mounds, and Enclosures, pp.285-297. Oxford: Archaeopress.

Jerome, P. 2002 Boobarran Ngummin: The Bunya Mountains. Queensland Review 9:1-5.

Jones, R. and N. White 1988 Point blank: Stone tool manufacture at the Ngilipitji Quarry, Arnhem Land, 1981. In R. Jones and B. Meehan (eds), Archaeology with Ethnography: An Australian Perspective, pp.51-87. Canberra: Department of Prehistory, Research School of Pacific Studies, Australian National University.

Kopytoff, I. 1986 The cultural biography of things: Commoditization as process. In A. Appadurai (ed.), The Social Life of Things: Commodities in Cultural Perspective, pp.64-91. Cambridge: Cambridge University Press.

Law, W.B., M.J. Slack, B. Ostendorf and M.M. Lewis 2017 Digital terrain analysis reveals new insights into the topographic context of Australian aboriginal stone arrangements. Archaeological Prospection 24(2):169-179. https://doi.org/10.1002/arp.1567 
Macdonald, G. 2001 Does 'culture' have 'history'? Thinking about continuity and change in central New South Wales. Aboriginal History 25:176-199.

Macknight, C.C. and W.J. Gray 1970 Aboriginal Stone Pictures in Eastern Arnhem Land. Canberra: Australian Institute of Aboriginal Studies.

McBryde, I. 1984 Kulin greenstone quarries: The social contexts of production and distribution of the Mt. William site. World Archaeology 16(2):267-285.

McCarthy, F.D. 1940 Aboriginal stone arrangements in Australia. The Australian Museum Magazine 2:184-189.

McNiven, I.J. 2004 Saltwater people: Spiritscapes, maritime rituals and the archaeology of Australian Indigenous seascapes. World Archaeology 35(3):329-349. https://doi.org/10.1080/0043824042 000185757

Meehan, B. and R. Jones 2005 Stone tool use in a land without stone: Ethnographic notes from the Gu-jingarliya. In I. MacFarlane, M.J. Mountain and R. Paton (eds), Many Exchanges: Archaeology, History, Community and the Work of Isabel McBryde, pp.147-170. Aboriginal History Monograph 11. Canberra: Aboriginal History Inc.

Morphy, H. 1995 Landscape and the reproduction of the ancestral past. In E. Hirsch and M. O'Hanlon (eds), The Anthropology of Landscape: Perspectives on Place and Space, pp.184-209. Oxford: Clarendon Press.

Mosely, B. 2010 Agency and archaeological material culture: Willing a suspension of disbelief? In C. Phillips and H. Allen (eds), Bridging the Divide: Indigenous Communities and Archaeology into the 21st Century, pp.61-80. Walnut Creek, CA: Left Coast Press.

Mullins, B., T. Cook and J. Gerritsen 1982 Aboriginal Lore of the Western Plains. Balmain East, NSW: Mulavon Pty Ltd.

O'Connor, S. 1987 The stone house structures of High Cliffy Island, north west Kimberley, WA. Australian Archaeology 25:30-39.

O'Connor, S., L. Zell and A. Barham 2007 Stone constructions on Rankin Island, Kimberley, Western Australia. Australian Archaeology 64:9-14. https://doi.org/10.1080/03122417.2007. $\underline{11681845}$

Piotto, E.L. 2012 Understanding Choice: Aboriginal Law and Decision-Making in the Selection of Rocks for a Stone Arrangement. Unpublished BA Honours thesis, University of Queensland, Brisbane.

Povinelli, E.A. 1995 Do rocks listen? The cultural politics of apprehending Australian Aboriginal labour. American Anthropologist 97(3):505-518. https://doi.org/10.1525/aa.1995. $\underline{97.3 .02 \mathrm{a} 00090}$

Rose, D.B. 1996 Nourishing Terrains: Australian Aboriginal Views of Landscape and Wilderness. Canberra: Australian Heritage Commission.

Ross, A. 2008 Managing meaning at an ancient site in the 21st century: The Gummingurru Aboriginal Stone Arrangement on the Darling Downs, southern Queensland. Oceania 78(1):91-108. https://doi.org/10.1002/j.1834-4461.2008.tb00030.x

Ross, A., B. Anderson and C. Campbell 2003 Gunumbah: Archaeological and Aboriginal meanings at a quarry site on Moreton Island, southeast Queensland. Australian Archaeology 57:75-81. https://doi.org/10.1080/03122417.2003.11681764

Ross, A. and S. Ulm 2010 Understanding Indigenous Knowledge Traditions at Gummingurru - Stage II: Recording and Excavation. 2008/004543 Interim Report to the Australian Institute of Aboriginal and Torres Strait Islander Studies, Canberra.
Ross, A., S. Ulm and B. Tobane 2013 Gummingurru - A community archaeology knowledge journey. Australian Archaeology 76:62-68. https://doi.org/10.1080/03122417.2013.11681966

Rowland, M. and S. Ulm 2011 Indigenous fish traps and weirs of Queensland. Queensland Archaeological Research 14:1-58. http://doi.org/10.25120/qar.14.2011.219

Rowlands, R.J. and J.M. Rowlands 1966 Aboriginal stone arrangements in the Western Desert of Australia. Mankind 6:355358.

Scott, C. 1996 Science for the west, myth for the rest? The case of James Bay Kree knowledge construction. In L. Nader (ed.), Naked Science: Anthropological Inquiry into Boundaries, Power, and Knowledge, pp.69-86. New York: Routledge.

Shanks, M. and C. Tilley 1987 Reconstructing Archaeology. Cambridge: Cambridge University Press.

Taçon, P.S.C. 1994 Socialising landscapes: The long-term implication of signs, symbols and marks on the land. Archaeology of Oceania 29(3):117-129. https://doi.org/10.1002/arco.1994.29.3.117

Thomas, E.J. and A. Ross 2013 Mapping an archaeology of the present: Counter-mapping at the Gummingurru stone arrangement site, southeast Queensland, Australia. Journal of Social Archaeology 13(2):220-241. https://doi.org/10.1177/1469605312470986

Thomas, E.J. and A. Ross 2018 Counter-mapping theory and its application to a constantly changing Aboriginal stone arrangement site. Australian Archaeology 84(1):56-66. https://doi.org/10.1080/ 03122417.2018.1455289

Tindale, N.B. 1974 Aboriginal Tribes of Australia: Their Terrain, Environmental Controls, Distribution, Limits and Proper Names. Canberra: Australian National University Press.

Torrence, R. 2005 Valued stone - How so? In I. MacFarlane, M.J. Mountain and R. Paton (eds), Many Exchanges: Archaeology, History, Community and the Work of Isabel McBryde, pp.357-372. Aboriginal History Monograph 11. Canberra: Aboriginal History Inc.

Towle, C.C. 1939 A bibliography of stone arrangements found in Australia. Mankind 2(7):216-221.

Whincop, M., L. Sheppard, A. Ross and A. Sneddon 2012 Bunya Mountains, Queensland - Identification, Assessment and Management of Indigenous Cultural Heritage Values Report to Burnett Mary Regional Group. UniQuest Project Number C00351.

Wobst, H.M. 2000 Agency in (spite of) material culture. In M-A. Dobres and J.E. Robb (eds), Agency in Archaeology, pp.40-50. London: Routledge.

Zimmerman, D.W. 2004 Inflation of Type 1 error rates by unequal variances associated with parametric, nonparametric, and ranktransformation tests. Psicológica 25:103-133.

Zimmerman, L.J. 2006 Consulting stakeholders. In J. Balme and A. Paterson (eds), Archaeology in Practice: A Student Guide to Archaeological Analyses, pp.39-58. Malden, MA: Blackwell Publishing.

Citation: Piotto, E.L., A. Ross, C. Perryman and S. Ulm 2018 Deliberate selection of rocks in the construction of the Gummingurru Stone Arrangement Site Complex, Darling Downs, Queensland. Queensland Archaeological Research 21:27-38. https://doi.org/ $\underline{10.25120 / \text { qar.21.2018.3649 }}$ 